
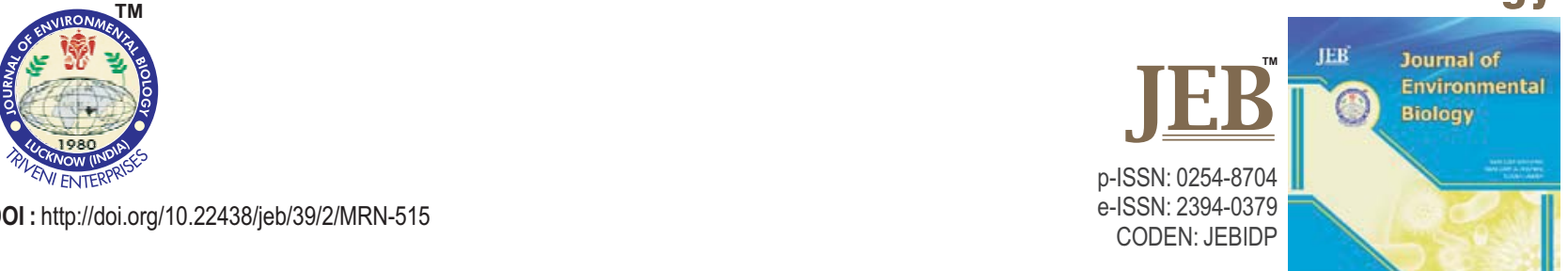

\title{
Comparative biosorption competencies of Ficus, Syzygium and Mangifera seeds for hexavalent chromium mitigation from polluted water
}

Authors Info

\section{S. Singh ${ }^{1}$, A. Tripathi ${ }^{1 *}$ and S.K. Srivastava ${ }^{2}$}

${ }^{1}$ Department of Applied Sciences, Institute of Engineering \& Technology, Dr. A.P.J. Abdul Kalam Technical University, Lucknow-226 021, India

${ }^{2}$ Central Ground Water Board, Ministry of Water Resources,

River Development \&

Ganga Rejuvenation, Lucknow - 226 021, India

${ }^{*}$ Corresponding Author Email alkatripathi2005@gmail.com

Key words

Biosorption

Ficus seeds

Hexavalent chromium

Mangifera seeds

Syzygium seeds

Publication Info

Paper received: 19.11 .2016

Revised received : 05.02.2017

Re-revised received : 04.06.2017

Accepted : 28.06.2017

\begin{abstract}
\end{abstract}
Aim : The dumped subsurface industrial wastes containing toxic metals have contaminated water resources because of their natural process leading to severe threat to flora, fauna and ecosystem in UPSIDC, Unnao area. The waste water contaminated chromium compounds can be purified through surface assimilation. The aim of the present study was to match sorption competencies of Ficus racemosa with Syzygium cumini and Mangifera cumini seed for chromium (VI) removal from polluted water.

Methodology : Chromium (VI) contaminated water samples were collected from UPSIDC sites, Unnao, Uttar Pradesh standardized and diluted to experimental strength. The sorption of $\mathrm{Cr}(\mathrm{VI})$ was investigated with relative competencies of biosorbents $(F$. racemosa, M. indica and $S$. cumini seeds) with retention time, sorbent dosage, temperature, chromium concentration and hydrogen ion activity. The biosorption was tested with various isopleths (Linear, Chemist and Freundlich).

Results : The sorption potential of F. racemosa seeds was of $10 \mathrm{mgg}^{-1}$ where as S. cumini and $M$. indica showed biosorption capacity of 13 and $21 \mathrm{mgg}^{-1} \mathrm{Cr}$ at neutral hydrogen ion activity scale. The surface assimilation was found highest at low $\mathrm{pH}$ scale range of two, rising with sorbent application quantity, temperature and decreased with higher $\mathrm{Cr}(\mathrm{VI})$ content.

Interpretation : The study reveals that biosorption efficiency decreased in the following order: $M$. indica $>S$ S. cumini $>F$. racemosa seed for hexavalent chromium from waste water.

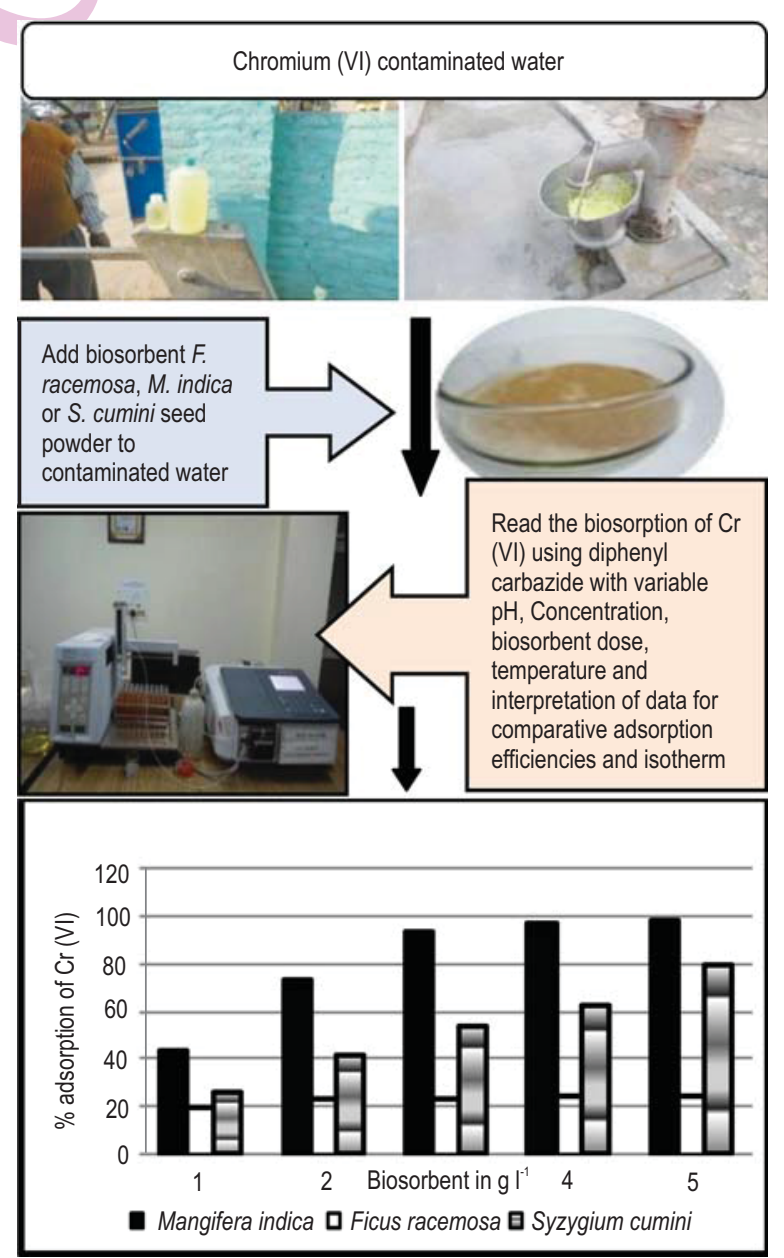




\section{Introduction}

The bioaccumulation tendency and toxic nature of water soluble metals like chromium, mercury, lead, arsenic and cadmium has caused significant menace to the environment (Chen et al., 2015). Currently, $\mathrm{Cr}(\mathrm{VI})$ is one of the significant hazardous metals in wastewater that are not degradable and highly immune to oxidization even at high temperatures. Physiologically, $\mathrm{Cr}$ compounds have been found as respiratory tract irritants and may cause pulmonic sensitization resulting in increased risk of respiratory organ, nasal and sinus cancer (Eastmond et al., 2008). Industrial out come of chromium (VI) compounds depends on factory and related to accrued threat of systema respiratorium. Ingestion of lethal dose of chromate can result in cardiovascular collapse. Oral exposure to chromium (VI) compounds may result in hematological toxicity. $\mathrm{Cr}(\mathrm{VI})$ compounds impact deoxyribonucleic acid damage, gene mutation, sister fibril exchange, body aberrations during a number of targets, including animal cells in vivo and animal and human cells in vitro (Eastmond et al., 2008). The reported management procedures for replacing $\mathrm{Cr}(\mathrm{VI})$ ions from wastewater have been replaced with new techniques like solidification, sorption on the charcoal (Lotfi et al., 2002), reduction, elution (Mauri et al., 2001), opposed osmosis, cation replacement (Rengaraj et al., 2003), separation at low temperature and electrolysis deposition strategies. The initial and subsequent running costs in afore said methods is very high as compared to sorption (Sharma et al., 2004), which is easy and appropriate technique (Dakiky et al., 2002; Gupta et al., 2006 , 2008) for removing Cr from waste water to make it potable (BIS, 2012). Enormous plant resources / thrown away commodities are usually available in rural (Kumar et al., 2016) from factories or unindustrialized byproducts (Palanisamy et al., 2015) that have competency to bind metal $\mathrm{Cr}$ (VI) through sorption (Nirmal Kumar et al., 2012). In most of the sorbent substances, the sorption capacity is low and creates a problem of their secure disposal on land / water. Consequently, the search for economical sorbent having high $\mathrm{Cr}(\mathrm{VI})$ sorption competency is the necessity of current time from available plant materials (Nourbakhsh et al., 1994; Bai et al., 2003) and unindustrialized waste products (Bailey et al., 1999).

Mangifera (Mango), Ficus (Fig) and Syzygium (Jamun) are economically important trees. It's fully grown-up primarily for its edible fruits and timber merchandise. The fruits of Ficus contain glauanol, sitosterol, aldohexose and alternative phytosterols (Padma, 2009). The phytochemical studies of Mangifera seeds have reported the presence of alkaloids, steroids, tannins, phenol, resins, organic compound and essential oil (Anjaneyulu et al., 1994). Similarly, composition of $S$. cumini seed contain organic compound jambosine and glycoside jambolin or antimellin (Muniappan, 2012). The bark of $F$. racemosa has been deliberated (Singh et al., 2013) and found to have outstanding sorption $\left(25.9 \mathrm{mgg}^{-1}\right)$ capacity of $\mathrm{Cr}(\mathrm{VI})$, however studies on the biosorption capacity of seed of $F$. racemosa is meager. In view of the above, the present paper aimed to analyze the biosorption efficiencies of $F$. racemosa, $M$. indica and S. cumini seeds for the removal of hexavalent chromium from surface and ground waters. The experimental impact of $\mathrm{pH}$ scale range, length of time, heat, chromium concentration, sorbent doses and equilibriums on surface assimilation were also investigated.

\section{Materials and Methods}

Preparation of standard $\mathrm{Cr}$ (VI) solution : The chromium (VI) contaminated surface and ground waters were collected from Unnao industrial areas of Uttar Pradesh (UPSIDC). The experimental reagents were of NIST grade $\mathrm{K}_{2} \mathrm{Cr}_{2} \mathrm{O}_{7}$ in deionized water and additional dilutions were made to desired concentrations for calibration. The contaminated samples were standardized against known $\mathrm{K}_{2} \mathrm{Cr}_{2} \mathrm{O}_{7}$ solution further diluted to experimental strength of $10-50 \mathrm{mgl}^{-1}$ with deionised water.

Preparation of biosorbent powder : The pulverized seeds of $F$. racemosa, $M$. indica and $S$. cumini obtained from local villages were used as biosorbent. The deionised water was used for washing and cleaning of seeds, dried in oven $\left(90-110^{\circ} \mathrm{C}\right)$ and airdried in open after grinding and sieving. The sorbent powder was preserved in air tight amber colored bottles in dark for experimental use. The sorbent grain size was of geometric mean $250 \mu \mathrm{m}$.

Screening of adsorbent: One hundred mg of each seed powder was tested as adsorbents during various experiments with identified $\mathrm{Cr}$ standard. The experiments were done by provocative the medium for a definite duration, temperature, dosage, medium hydrogen ion activity scale and concentration. The seed powder quantity was changeable one to five gram per liter for a range of experiments. The concentration of chromium solution experimented was $10-50 \mathrm{mgl}^{-1}$ and temperature studied was $10-40^{\circ} \mathrm{C}$ maintained in ice bath / thermoregulatory oven. The hydrogen ion activity scale of pH 2,4,7,10 and 12 was maintained by $0.01 \mathrm{~N} \mathrm{HCl}$ and $0.01 \mathrm{~N} \mathrm{NaOH}$ solution and monitored. The quantity of unreacted $\mathrm{Cr}(\mathrm{VI})$ in different experimental conditions (time, doses, metal concentration, medium, temperature) was calculated by reacting with 1, 5-diphenyl carbazide in pH scale 4-5 $(1: 1 \mathrm{HCl})$ by forming purple complex at $540 \mathrm{~nm}$ (APHA, 2012). The experiments were dispensed in triplicate and mean values were used for illustration and interpretation of figures. The Chemist (Langmuir, 1918), Freundlich (1928) isopleths model for sorption of fine seed particles of Syzygium cumini, Ficus racemosa and Mangifera indica for $\mathrm{Cr}(\mathrm{VI})$ has additionally been investigated.

\section{Results and Discussion}

The surface assimilation of $\mathrm{Cr}(\mathrm{VI})$ on absolutely different sorbents with time is specified in Fig. 1a. Sorption of chromium (VI) ions showed a linear function with time on F. racemosa seed up to $2 \mathrm{hrs}$ then slowed down.

Similar trend was also observed by M. indica (33\% to $43 \%$ ) and S. cumini seeds ( $17 \%$ to $27 \%$ ). A decrease in the rate of 

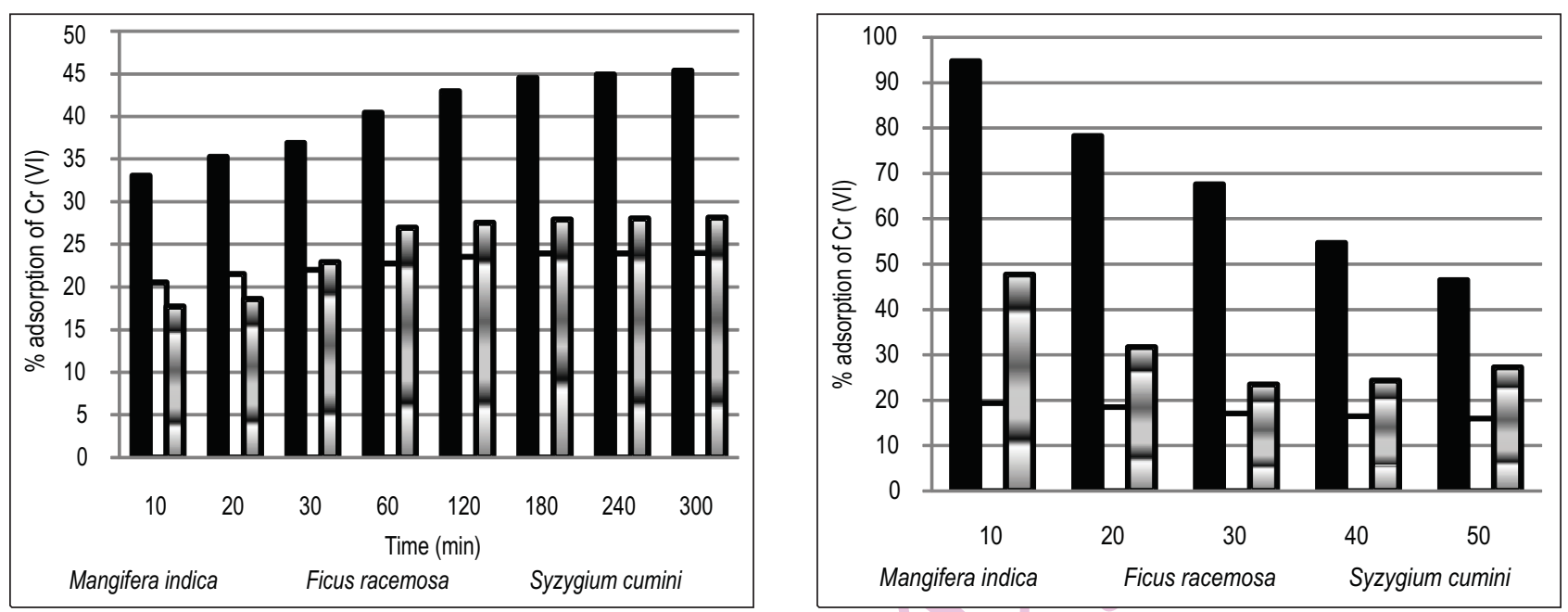

Fig. 1a : Effect of time duration on percentage adsorption of $\mathrm{Cr}(\mathrm{VI})$

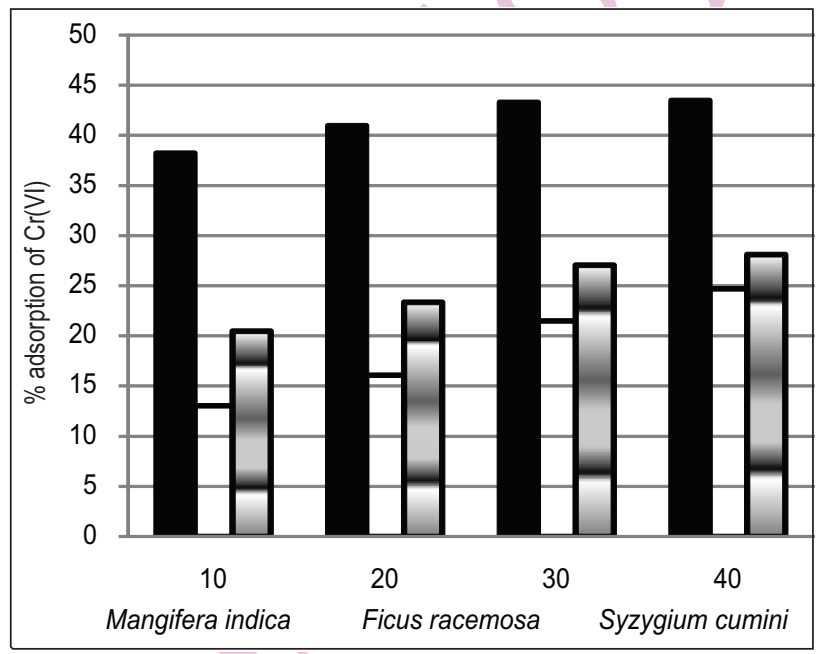

Fig. 1c : Effect of temperature $\left({ }^{\circ} \mathrm{C}\right)$ on $\mathrm{Cr}$ assimilation

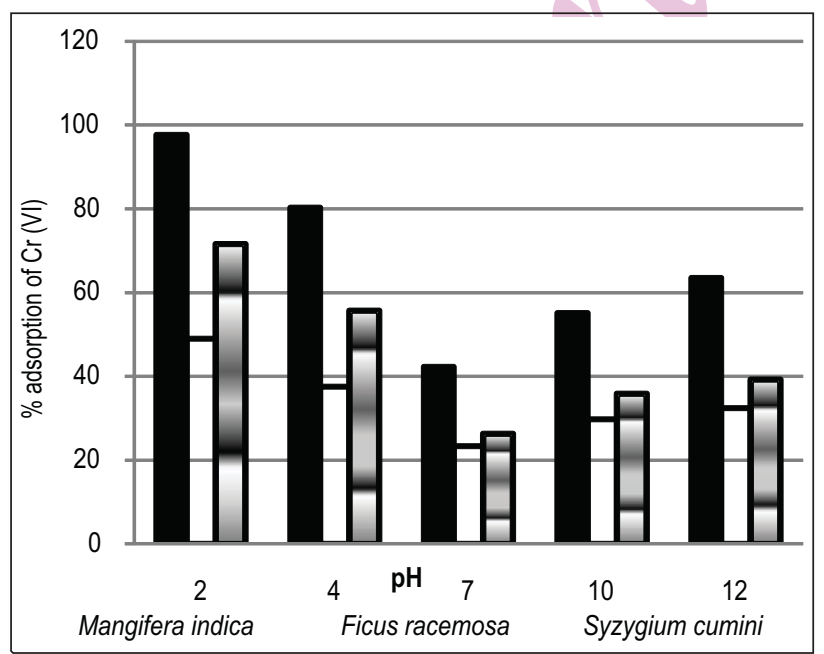

Fig. 1d : Effect of hydrogen ion activity on biosorption of $\mathrm{Cr}(\mathrm{VI})$

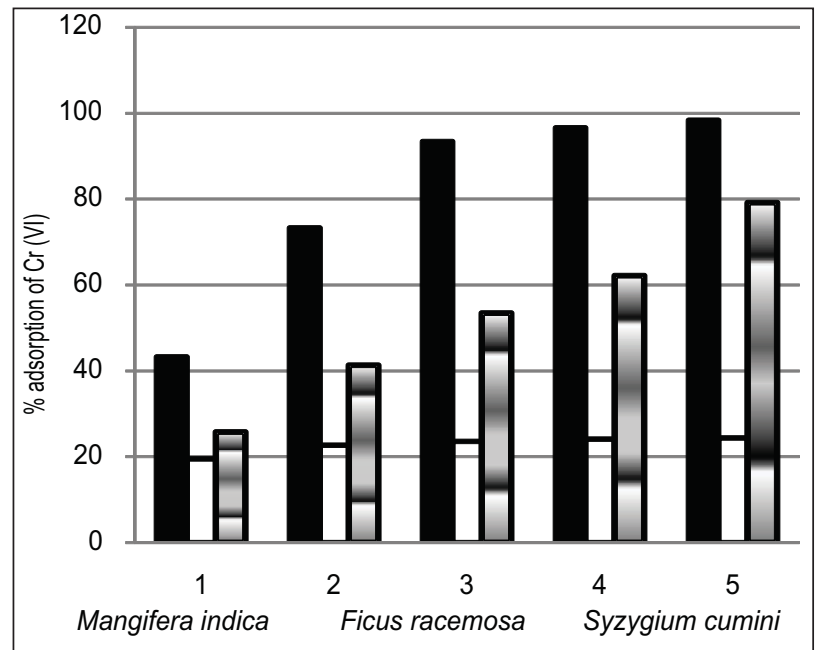

Fig. 1e : Effect of sorbent application $\left(\mathrm{gl}^{-1}\right)$ on $\mathrm{Cr}(\mathrm{VI})$ biosorption 


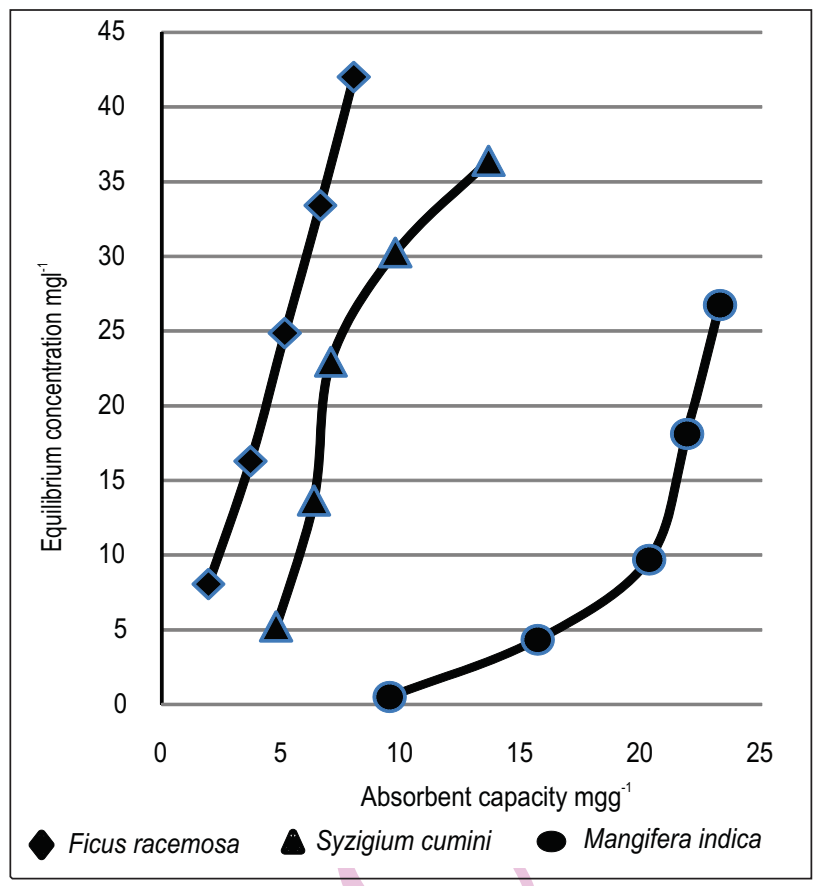

Fig. 2a : Linear sorption isotherm of $\mathrm{Cr}(\mathrm{VI})$

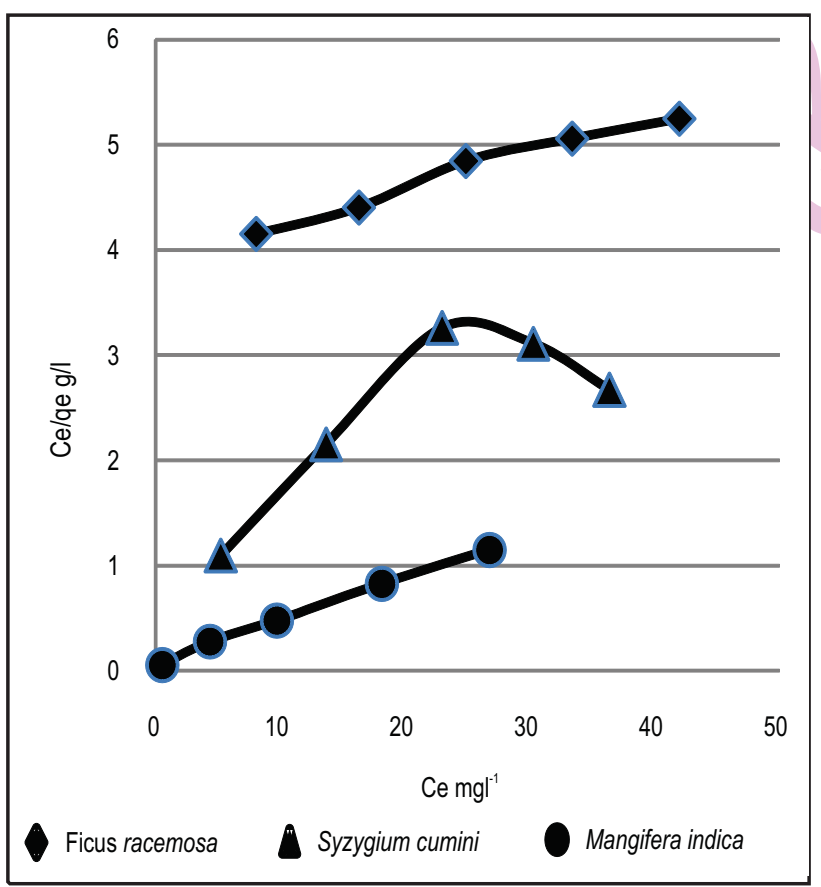

Fig. 2b : Langmuir representation for $\mathrm{Cr}(\mathrm{VI})$

natural process with time has also been reported by Aziz (2004) for elimination of iron metal treating with $\mathrm{CaCO}_{3}$ and Samdani et al. (2008) for chromium (VI) removal by Hydrilla. The positive sorption is additionally due to free sorption sites on the adsorbent surface as large numbers of vacant adsorbent sites were available

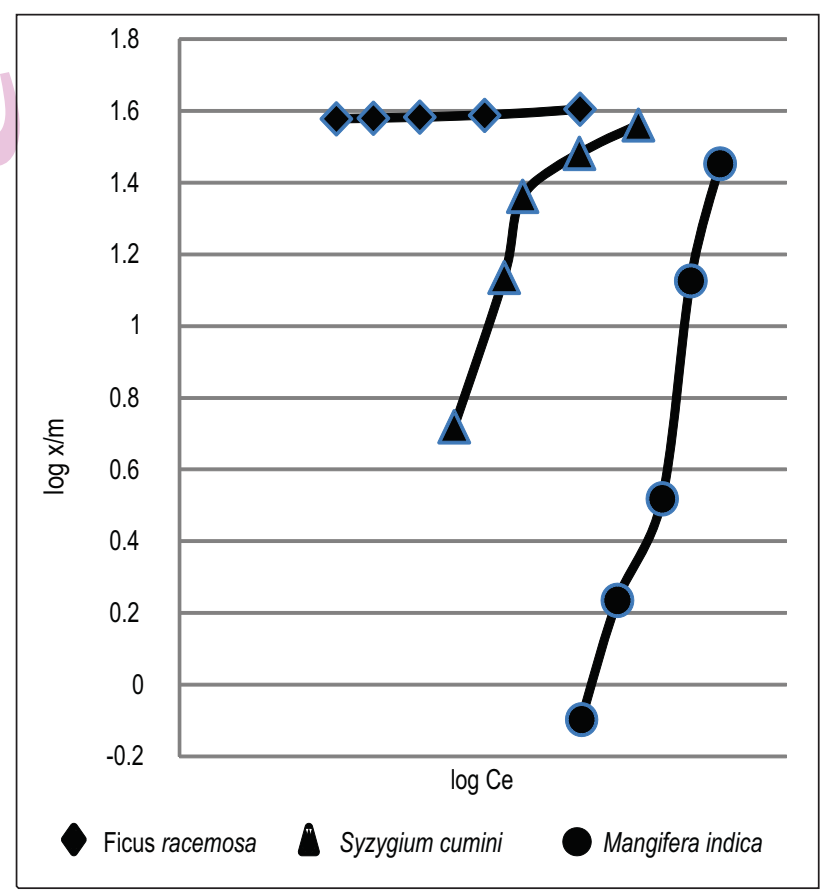

Fig. 2c : Freundlich representation for $\mathrm{Cr}(\mathrm{VI})$

for initial stage of sorption, thenceforth with lapse of time the remaining vacant surface sites were occupied and because of repulsive forces between the $\mathrm{Cr}$ molecules at the sorbent exterior, the speed of adsorption was decreased (Ucun et al., 2002). It was observed that $50 \mathrm{mgl}^{-1} \mathrm{Cr}$ was readily adsorbed by $M$. indica 
Table 1a : Langmuir constants of seed grain powders

\begin{tabular}{llll}
\hline $\begin{array}{l}\text { Sorbent } \\
\text { powder }\end{array}$ & Constant & $\left(\boldsymbol{R}^{2}\right)$ \\
\cline { 2 - 3 } & $\mathbf{q}_{\mathrm{m}}\left(\mathrm{mgg}^{-1}\right)$ & $\mathbf{b}\left(\mathrm{Img}^{-1}\right)$ & \\
\hline F. racemosa & 5.13 & 0.033 & 0.976 \\
M. indica & 11.37 & 0.339 & 0.998 \\
& 20.29 & 0.041 & 0.996 \\
& 21.64 & 0.120 & 0.998 \\
& 21.12 & 0.046 & 0.935 \\
S. cumini & 20.21 & 0.130 & 0.994 \\
& 9.73 & 0.004 & 0.972 \\
& 13.53 & 0.345 & 0.993 \\
& 13.15 & 0.099 & 0.913 \\
& 13.48 & 0.392 & 0.991 \\
\hline
\end{tabular}

Table $1 \mathrm{~b}$ : Freundlich constants for $\mathrm{Cr}(\mathrm{VI})$

\begin{tabular}{llll}
\hline $\begin{array}{l}\text { Sorbent } \\
\text { material }\end{array}$ & \multicolumn{2}{l}{ Constant } & $\left(R^{2}\right)$ \\
\cline { 2 - 3 }$K_{\mathrm{F}}$ & $1 / \mathrm{n}$ & \\
\hline F. racemosa & 3.006 & 0.853 & 0.999 \\
M. indica & 1.117 & 0.234 & 0.989 \\
& 1.084 & 0.211 & 0.961 \\
S. cumini & 1.986 & 0.472 & 0.827 \\
& 2.518 & 0.421 & 0.821 \\
\hline
\end{tabular}

followed by S. cuminiand F. racemosa seeds, and there after the rate of biosorption was found to decrease with contact time (Fig. 1a)

Charcoal prepared from fish bone was used as sorbent material for halide ion by Killedar and Bhargava (1990). The sorption rate on fig seed powder increased to $19.4 \%$ and subsequently it decreased (Fig. 1b), where as in M. indica and S. cumini seed it was determined 94.8 and $47.7 \%$ at contact time of $120 \mathrm{~min}$. The percentage removal was found to decrease exponentially at high $\mathrm{Cr}$ concentrations due to unavailability of active sites on adsorbent as a result of saturation (Gupta et al., 2006). Similar conclusions were drawn by Samdani et al., (2008) using aquatic plant as biosorbent and Sasikala et al., (2015) for chromium (VI) surface assimilation by Moringa oleifera.

The impact of high temperature on chromium (VI) sorption was found in linear correlation with temperature and analogous conclusions were conjointly found by Sasikala et al. (2015) within which they used Moringa species for chromium. The sorbent (fig, mango and jamun seed fine particles) showed sorption efficacy directly proportional to the rising temperature, indicating an energy captivating phenomenon (Fig. 1C).

The effect of hydrogen ion activity on surface assimilation of $\mathrm{Cr}(\mathrm{VI})$ is specified in Fig. 1d. Sasikala et al., (2015) reported that surface assimilation of metal ions increase at acidic $\mathrm{pH}$ values and $\mathrm{H}^{+}, \mathrm{Cr}^{3+}$ and $\mathrm{Cr}^{6+}$ ions present in solution vie for the active sites of sorption. The low proton activity range of $\mathrm{pH}$ over eight was found to metal hydroxide configuration turning to solidification. The highest assimilation of chromium (VI) on fig seed was discovered at higher proton activity $(\mathrm{pH}-2)$ that decreased slowly at neutral and further rose at lower proton activity (pH-12, Fig. 1d) similar to S. cumini and M. indica seeds, however $M$. indica seed in high hydrogen activity showed vital biosorption up to $97 \%$.

At neutral pH, the sorption of $\mathrm{Cr}(\mathrm{VI})$ on $\mathrm{S}$. cumini was analogous to $F$. racemosa seed. Analogous explanation of exceptional sorption of chromium $\mathrm{VI}$ in acidic medium decreased at neutral medium using Hydrilla verticeillata (Samdani et al., 2008) and Aspergillus niger biomass (Chhikara and Dhankhar, 2008). Park et al. (2008) reported that at acidic medium the predominant anionic varieties of hexavalent chromium $\mathrm{HCrO}_{4}^{-}, \mathrm{CrO}_{4}^{-}, \mathrm{Cr}_{2} \mathrm{O}_{7}^{-}$type strong electro static attraction with cationic sorbent, $-\mathrm{COOH}$ and $-\mathrm{NH}_{x}$ species lead to increased sorption at high hydrogen ion activity range. The hydrolysis of esters and amide linkage in sorbent material molecules in acidic / basic medium results in formation of free $\mathrm{COOH}$ and $-\mathrm{NH}_{\mathrm{x}}$ species having lepton donor nitrogen and oxygen atoms sites for $\mathrm{Cr}$ bindings resulting to increase in sorption. The acid catalyzed hydrolysis of phyto chemicals in $M$. indica seed (Anjaneyulu et al., 1994) results more free amino and carbonyl electron donor moieties compared to $S$. cumini and F. racemosa (Padma, 2009), hence more adsorption observed in high hydrogen ion activity range.

The percentage change in surface assimilation of adsorbent S. cumini $(25.7 \%$ to $79.1 \%)$, F. racemosa $(19.5 \%$ to $24.4 \%$ ) and $\mathrm{M}$. indica (43.2\% to $98.4 \%$ ) seed for $\mathrm{Cr}(\mathrm{VI})$ was directly correlated with the quantity of sorbent (Fig. 1e).

The outstanding high percentage surface assimilation more than 98 was found in seeds of $M$. indica, which enhanced with sorbent quantity. Sasikala et al. (2015) reported the parallel results during $\mathrm{Cr}$ elimination by Moringa oleifera and Regina de Moreira et al. (2010) ferric mitigation applying carbon as sorbent. The boost in surface assimilation of chromium (VI) with rising biosorbent application quantity showed that further and additional active sites becomes accessible on the outer surface of biosorbent for chromium particles to adsorb (Rio et al., 2002).

Sorption isopleths : The necessary physical-chemical aspect for the analysis of the sorption is the quantity of different material phases in equilibrium media. The sorption was studied in different experimental environment of quantity and chromium application at stable temperature. The stability between the quantities of chromium (VI) within the solution to its concentration on the solid exterior (mass of chromium (VI) / unit mass of sorbent) is represented in Fig. 2a.

The interpretation infers that sorption capability will enhance with increasing chromium (VI) concentration at equilibrium. As depicted in Fig. 2a, the surface assimilation ability of $M$. indica seed was higher $\left(23 \mathrm{mgg}^{-1}\right)$ for the equilibrium $\mathrm{Cr}$ quantity (Ce) of $26 \mathrm{mgl}^{-1}$, while in $S$. cumini it was $13 \mathrm{mgg}^{-1}$ for 36 $\mathrm{mgl}^{-1} \mathrm{Ce}$. The adsorbent competency of Mangifera seed towards 
Cr removal was greater than Syzygium and Ficus seeds at same equilibrium concentration.

The sorbent $F$. racemosa, $M$. indica and $S$. cumini seeds for $\mathrm{Cr}(\mathrm{VI})$ is represented for Langmuir (Chemist) isopleths in Fig. $2 \mathrm{~b}$, which shows the equilibrium quantity of $\mathrm{Cr}(\mathrm{VI})$ in soluble form and adsorbed solid phase. The low values of Ce/qe (Fig. 2b) indicate higher sorption capacity found in Mangifera and Syzygium as compared to Ficus.

The $R^{2}$ constant was close to one $(0.998$, Table $-1 \mathrm{a})$, which indicate a decent harmonization with the equilibrium $\mathrm{Cr}$ quantity and sorption competency. The sorption capability (qm) to generate a single coating on exterior was found to be maximum $21.64 \mathrm{mgl}^{-1}$ for M. indica, $13.53 \mathrm{mgl}^{-1}$ for S. cumini and $11.37 \mathrm{mgl}^{-1}$ for $F$. racemosa at neutral medium. The adsorption energy was 0.130 (M. indica), 0.339 (F. racemosa) and 0.392 (S. cumini) I $\mathrm{mg}^{-1}$ showing active chromium (VI) sorption conditions (Hall etal., 1966).

The Freundlich isopleth (Fig. 2c) and constants (Table 1b) showed $R^{2}$ close to unity (0.999) conforming the Freundlich equation. Kadirvelu and Namasivayam, 2000; Qaiser et al., 2005 found that intensity of biosorption (n) between one and ten showed positive active sorption. The magnitude of Kf and $n$ shows straight forward sorption of significant metal ion and high adsorption capacity (Ahalya et al., 2005). Distribution of metal ions on the biosorbent surface was found to over unity (n values), indicating active adsorption.

The comparative sorption competencies increased in the following order $F$. racemosa $<$ S. cumini $<M$. indica seed $(11,13$ and $23 \mathrm{mgg}^{-1}$ ) for chromium (VI) at neutral pH scale. The highest sorption occurred at high sorbent doses, low hydrogen ion activity, increase in temperature and low $\mathrm{Cr}(\mathrm{Vl})$ concentration within two hour duration and the process also confirmed the isopleths applications.

\section{Acknowledgments}

Authors are grateful to the Dean, Faculty of Sciences, Institute of Engineering and Technology, Lucknow and Er. Kiriti Bhushan Biswas, Chairman, Central Ground Water Board, Faridabad for providing laboratory infrastructures.

\section{References}

Ahalya, N., R. D. Kanamadi and T. V. Ramachandra: Biosorption of $\mathrm{Cr}$ (VI) from aqueous solutions by the husk of Bengal gram (Cicer arientinum). Electron J. Biotechnol., 8, 258-264 (2005)

Anjaneyulu, V., I. S. Babu and J. D. Connolly: Hydroxymangiferonic acid from Mangifera indica. Phytochemistry, 35, 1301-1303 (1994)

Aziz, H. A.: Physicochemical removal of iron from semi aerobic landfill leachable by limestone filter. Waste Manag., 24,353-358 (2004)

APHA: Standard Methods for the Examination of Waste and Wastewater, 22nd Edn., American Public Health Association, AWWA, Washington, D.C. (2012)

Bai, R.S. and E. Abraham : Studies on chromium (VI) adsorption- desorption using immobilized fungal biomass. Biores. Technol., $87,17-26(2003)$

Bailey, S.E., T.J. Olin, R.M. Bricka and D. Adrian: A review of potentially low-cost sorbents for heavy metals. Water Res., 33, 2469-2479 (1999)

BIS IS: 10500, Indian Standard : Drinking Water-Specification, first revision. Bureau of Indian Standards, New Delhi, India (2012)

Chen, M., P. Xu, G. Zeng, C. Yang, D. Huang and J. Zhang: Bioremediation of soils contaminated with polycyclic aromatic hydrocarbons, petroleum, pesticides, chlorophenols and heavy metals by composting: Applications, microbes and future research needs. Biotechnol. Adv., 33, 745-755(2015)

Chhikara, S. and R. Dhankhar: Biosorption of $\mathrm{Cr}(\mathrm{VI})$ ions from electroplating industrial effluent using immobilized Aspergillus niger biomass. J. Environ. Biol., 29, 773-8 (2008)

Dakiky, M.,A. Khami, A. Manassra and M. Mereb: Selective adsorption of chromium (VI) in industrial waste water using low cost abundantly available adsorbents. Adv. Environ. Res., 6, 533-540 (2002)

Eastmond David, A., J. T. Mac Gregor and R. S. Slesinski : Trivalent chromium: Assessing the genotoxic risk of an essential trace element and widely used human and animal nutritional supplement. Critical Rev. Toxicol., 38, 173-190 (2008)

Freundlich, H.: Colloid and Capillary Chemistry. E.P. Dutton and Co., New York (1928)

Gupta, S. and B.V. Babu : Adsorption of Chromium (VI) by low cost adsorbent prepared from tamarind seed. J. Environ. Eng. Sci., 7, 553-557 (2008)

Gupta, S. and B. V. Babu: Adsorption of Cr (VI) by a low-cost adsorbent prepared from neem leaves, Proceedings of National Conference on Environmental Conservation (NCEC-2006), BITS-Pilani, pp. 175-180 (2006)

Hall, K. R., L.C. Eagleton, A. Acrivas and T. Vermuelen: Pore and solid diffusion kinetics in fixed bed adsorption under constant pattern condition. Ind. Eng. Chem. Fund., 5, 212-223 (1966)

Kadirvelu, K. and C. Namasivayam: Agricultural by-products as metal adsorbents. Sorption of lead (II) from aqueous solutions on to coirpith carbon. Environ. Technol., 21, 1091-1097 (2000).

Killedar, D. J. and D. S. Bhargava: Feasibility of fluoride adsorption on fishbone charcoal. J. Inst. Eng. (India), Environ. Eng. Div., 70, 4749 (1990)

Kumar, A. and V. Kumar: Equilibrium and thermodynamic studies of $\mathrm{Cd}$ (II) biosorption by chemically modified orange peel. J.Environ. Biol., 37, 201-206 (2016)

Langmuir, I. : The sorption of gases on plane surfaces of glass, mica and platinum. J.American Chem. Soc., 40, 1361-1403 (1918)

Lotfi, M. and N. Adhoum: Modified activated carbon for the removal of copper, zinc, chromium and cyanide from wastewater. Separ. Purif. Technol., 26, 137-146 (2002)

Mauri, R., R. Shinnar, M.D. Amore, P. Giordano and A. Volpe: Solvent extraction of chromium and cadmium from contaminated soils. American Inst. Chemical Eng. J., 47, 509-512 (2001).

Muniappan, A. and P. S. Babu: Syzygium cumini (L.) Skeels-A review of its phytochemical constituents and traditional uses Asian Pacific $J$. Tropical Biomed., 2, 240-246 (2012)

Nirmal Kumar, J.I. and C. Oommen: Removal of heavy metals by biosorption using freshwater alga Spirogyra hyaline. J. Environ. Biol., 33, 27-31 (2012)

Nourbakhsh, M., Y. Sag, D. Ozar, Z. Aksu and C. Kutsal : A comparative study of various biosorbents for removal of chromium (VI) ions from industrial waste waters. Process Biochemistry, 29, 1-5(1994)

Padma, M. P. : Ficus racemosa : An overview, Natural Products Radiance, 8, 84-90 (2009) 
Palanisamy, S. B. and A. Balaiah: Biosorption of chromium (VI) onto $\mathrm{NaOH}$ activated Codium tomentosum biomass. J. Environ. Biol., 36, 1381-1388 (2015)

Park, D., S. R. Lim, Y. S. Yun and J. M. Park: Development of new Cr VI biosorbent from agriculture bio waste. Bioresour. Technol., 99, 8810-8818 (2008)

Qaiser, S. R., S. Anwar and U. Muhammad: Biosorption of lead (II) and chromium (VI) on groundnut hull: Equilibrium, kinetics and thermodynamics study. Electronic J. Biotechnol., 12, ISSN: 07173458 (2009)

Regina de Moreira, F. P. M., V. S. Madeira, H. J. Jose and E. Humeres: Removal of iron from water using adsorbent carbon. Separ. Sci. Technol., 39, 271-285(2010)

Rengaraj, S., Joo, C.K. Kim and J. Yi.: Kinetics of removal of chromium from water and electronic process wastewater by ion exchange resins: 1200H, 1500H and IRN97H. J. Hazard. Mat., 102, 257-275 (2003).

Rio, M., A. V. Parvate and A. G. Bhole: Removal of $\mathrm{Cr}^{6+}$ and $\mathrm{Ni}^{2+}$ from aqueous solution using bagase and fly ash. Waste Manag., 22, 821-830 (2002).

Samdani, S., S. J. Attar, C. Kadam and S. S. Saral: Treatment of $\mathrm{Cr}(\mathrm{VI})$ contaminated waste water using biosorbent Hydrilla verticillata Int. J. Engg. Res. Indu. App., 1, 271-282 (2008)

Sasikala, S. and G. Muthuraman: Chromium (VI) removal using biosorbents derived from Moringa oleifera. Ind. Chem., 1, doi : 10. 4172/2469-9764.1000105(2015)

Sharma, A. and K. G. Bhattacharyya : Adsorption of chromium (VI) on Azadirachta indica (Neem) leaf powder. Adsorption, 10, 327-338 (2004)

Singh, S., A. Tripathi, S. K. Srivastava and R. Prakash: Biosorption of chromium (VI) on Ficus racemosa bark powder. Int. J. Chem. App., 5, 237-249(2013)

Ucun, H., Y. K. Bayhan, Y. Kaya, A. Cakici and O. P. Algur: Biosorption of chromium VI from aqueous solution by concn biomass of Pituis sylvestris. Biores. Technol., 85, 155-158 (2002) 